\title{
Performance investigation of Air-conditioning system using ejector as expansion device
}

\author{
Harish Choudhary*, B.S.Kothavale and K.V.Mali \\ ${ }^{\dagger}$ Department of Mechanical Engineering, MIT College of Engineering, Savitribai Phule Pune University, India \\ Accepted 15 June 2016, Available online 20 June 2016, Special Issue-5 (June 2016)
}

\begin{abstract}
This paper discusses the use of Ejector as an expansion device as an energy efficient alternative to expansion valve in air conditioning system to improve the system performance. Expansion Process in Vapour Compression refrigeration system represents one of the important sources of irreversibility. Ejector was used instead of conventional expansion device which not only recover the expansion process loss by generating isentropic expansion process but also by increasing the cooling capacity and decreasing the power consumption. Initially experimental test was conducted on window air conditioner with standard expansion valve and then with ejector .Test were also conducted to re-circulate the liquid at the outlet of evaporator if any by using separator through valve to ejector. These act as secondary flow which was controlled by using hand valve. The coefficient of performance (COP) values for both conventional and modified ejector systems were experimentally investigated under same external conditions. Modified ejector refrigeration system shows $20 \%$ improvement in COP as compared with conventional system.
\end{abstract}

Keywords: Ejector, window air conditioning system, cooling capacity, power consumption.

\section{Introduction}

Vapour compression cooling cycles deviate from the Carnot refrigeration cycle in several ways, such as isenthalpic expansion of saturated liquid at the condenser outlet and desuperheating of refrigerant vapour at the compressor outlet. Therefore, COPs of vapour compression cooling cycles are always lower than those of a Carnot cycle under the same working conditions. Isenthalpic expansion imposes a double penalty on cycle performance compared with isentropic expansion in the Carnot cycle: the cooling capacity is reduced and the compressor work is increased. Expansion work recovery devices such as ejectors which recover the kinetic energy released during the expansion instead of wasting it in a throttling process are known to be useful to cycle performance.

This loss is due to kinetic energy consumption by swirl flow in the expansion valve. No studies regarding the expansion-valve cycle have focused on this energy loss in the expansion valve. If expansion energy loss can be eliminated and the energy otherwise lost used as compressor power, it is possible to improve refrigerating capacity while at the same time lowering compressor power consumption.

An ejector is an ideally isentropic expansion device capable of recovering the work that is otherwise lost

*Corresponding author: Harish Choudhary by the isenthalpic throttling process associated with the expansion valve in conventional air-conditioning cycles. In an ejector, a high-pressure motive stream is expanded through a converging-diverging nozzle (motive nozzle) to a low pressure and high velocity. At the same time, a low-pressure suction stream enters the ejector through a separate, generally converging only, nozzle (suction nozzle) and is entrained by the motive fluid through momentum transfer between the two streams. After mixing has occurred between the two streams, they enter a diffuser, where they are further decelerated and compressed to a pressure higher than the initial pressure of the suction stream. Thus, the effect of the ejector is to provide a pumping effect to the suction stream by means of expansion of the motive stream.

\section{Literature Review}

Disawas and Wongwises experimentally investigated the performance of ejector refrigeration system. They proposed that, in addition to serving as an expansion device, the ejector can also act as a refrigerant pump for the low-pressure side of the system. The evaporator is therefore flooded with refrigerant and operates as in a liquid recirculation system. Their experimental results showed that the COP of the two-phase ejector refrigeration cycle using R134a was higher than that of the baseline cycle using expansion valve over the whole range of experimental conditions. The maximum 
improvement achieved was about $13 \%$ at low heat sink and heat source temperatures. Less attention has been given to low-pressure working fluids in the literature for ejector cooling cycles compared with R744 due to their lower work recovery potential. However, ejector cooling cycles using low-pressure refrigerants, such as R134a or R1234yf, can still have noticeable performance improvements.

Nehdi et al. numerically investigated that replacing the throttle valve with a two-phase ejector improved COP up to $22 \%$ in a vapour compression system using R-141b as refrigerant. Bilir and Ersoy performed experiment refrigeration system using two phase ejector as expander. It was found that depending on operating condition, the work recovery in the ejector was $14 \%$ and $17 \%$.Their experimental showed that COP of ejector refrigeration system was $6.2-14.5 \%$ higher than that of conventional system.

Pottker and Hrnjak experimentally tested an R410A EEC and reported improvements from $8.2 \%$ to $14.8 \%$ over the basic system. Lawrence and Elbel experimentally investigated the performance of an alternate two phase ejector refrigeration system. Maximum COP improvement of 8\% with R134a and $12 \%$ with R1234yf was found. Sumeru et al numerically and experimentally investigated alternate ejector refrigeration cycle in air conditioning system which shows increased in COP of 4.17, 11.14 and $13.78 \%$ at ambient temperature of 30,35 and $40{ }^{\circ} \mathrm{C}$ respectively.

\section{Standard and modified ejector cycle}

\subsection{Standard Ejector refrigeration system}

Two-phase ejector-expansion refrigeration cycle along with P-h diagram is shown in figure. It consist of two extra components i.e. ejector and separator as compared with conventional system. The high pressure liquid refrigerant coming out from condenser is expanded through motive nozzle of the ejector. This expansion of the high-pressure liquid refrigerant is useful to entrain and raises the vapour pressure of refrigerant at the outlet of the evaporator. This expansion of the high-pressure liquid refrigerant is useful to entrain and raises the vapour pressure of refrigerant at the outlet of the evaporator. Liquid refrigerant coming from outlet of condenser is called primary flow and flow coming from evaporator outlet is called secondary flow. Mixing of both the fluid takes place in mixing chamber. At Diffusion nozzle, fluid is decelerated, hence pressure will increase. This pressure is higher than initial pressure of suction stream.

At the outlet of the ejector the two-phase fluid is sent to the liquid-vapour separator, where the vapour refrigerant enters the compressor and finally becomes the motive stream, while the liquid refrigerant returns to the evaporator through a throttle valve and finally becomes the suction stream. Due to higher compressor inlet pressure, work of compression is reduced as compared with basic cycle. Evaporator cooling capacity is also increased since evaporator is flooded with liquid refrigerant at the inlet of evaporator. Hence COP of the system also increases.
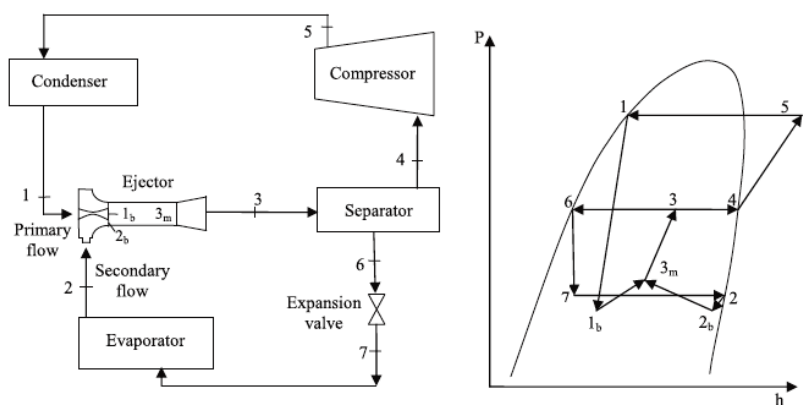

Fig. 1 Ejector refrigeration cycle with P-h diagram

\subsection{Modified Ejector refrigeration system}

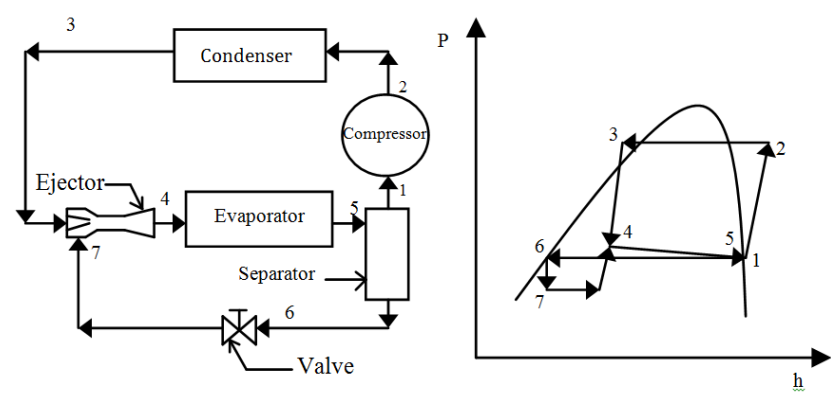

Fig.2 Modified ejector refrigeration cycle

Figure shows the layout diagram of modified ejector refrigeration system. It has small modification as compared to standard ejector refrigeration system. High pressure liquid refrigerant at the outlet of condenser is expanded in motive nozzle, which act as primary flow .At proper valve opening position, liquid at lower part of separator is sucked due to pressure difference and act as secondary flow. In the mixing chamber, fluid is decelerated further in diffusion section and compressed to a pressure higher as compared with initial pressure of the suction stream. The fluid at the outlet of the ejector is sent to the evaporator. Outlet of evaporator is send to liquidvapour separator, where the vapour enters the compressor which act motive stream, while the liquid refrigerant which returns to the evaporator through a hand valve becomes the suction stream. Hence flow can be controlled by regulating hand valve.

\section{Experimental setup without Ejector}

First the performance of air conditioning system was tested without ejector and theoretical and actual coefficient of performance was calculated for existing window air conditioning system. 


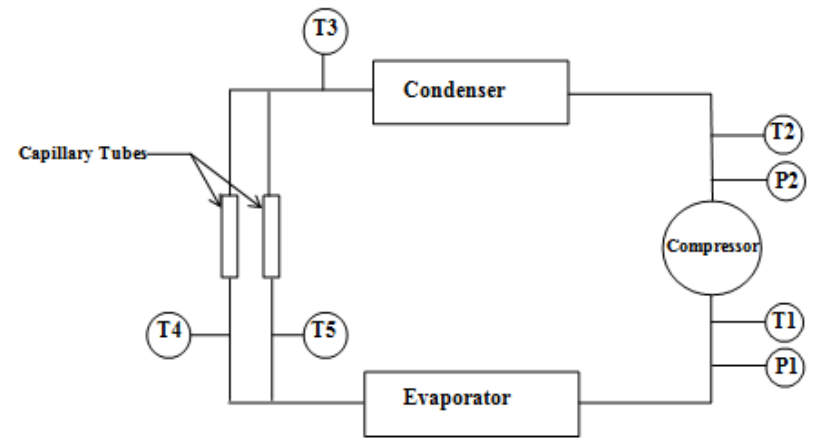

Fig. 3 Schematic of experimental setup without ejector

Figure shows schematic layout of experimental setup without ejector. Two pressure gauges were used to measure inlet and outlet pressure of compressor. Five thermocouples were used at various positions as shown in figure.

Power consumed by window air conditioning system was calculated by using wattmeter. To have steady reading, total ten reading were taken at an interval of 10 minutes. Coolpack was used to draw actual and ideal cycle. Coolpack is a collection of simulation tools for refrigeration prepared by Department of Energy Engineering, Technical University of Denmark.

Actual cooling capacity was calculated by one of the simplest methods where dry and wet bulb temperature were calculated at lower compartment where air flows in over the cooling coils of evaporator and at upper compartment where cooled air thrown out were calculated by pychrometer. Mass flow rate was calculated by measuring velocity at lower and upper compartment. Anemometer was used to measure velocity.

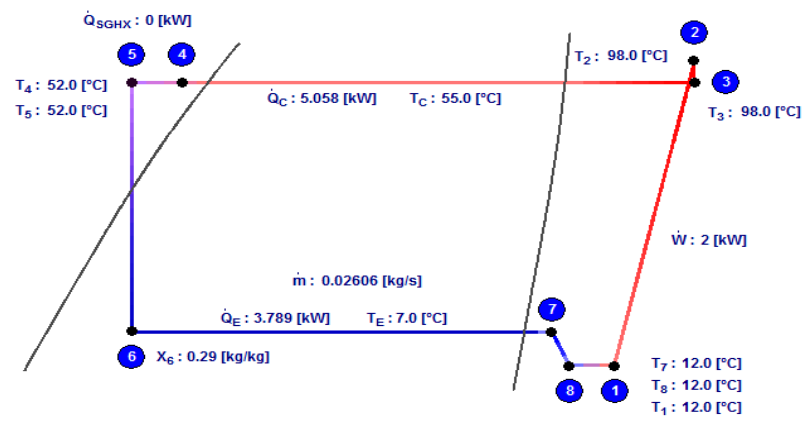

Fig. 4 Actual cycle drawn in coolpack software

Figure shows cycle of vapour compression system without ejector drawn using Coolpack. Cycle shows Evaporation cooling capacity and heat rejection by condenser.

\section{Experimental with ejector Setup}

Figure shows the layout diagram of experimental setup with ejector. Ejector,separator,valve were the extra component used to make changes in the system.

These changes were made in same window air conditioner. Experimental setup consist thermocouples which measure temperature at various places namely $\mathrm{T} 1, \mathrm{~T} 2, \mathrm{~T} 3, \mathrm{~T} 4, \mathrm{~T} 5, \mathrm{~T} 6, \mathrm{~T} 7$ and three pressure gauges P1,P2,P3 were used. Hand valve was used to control the flow from separator to ejector.

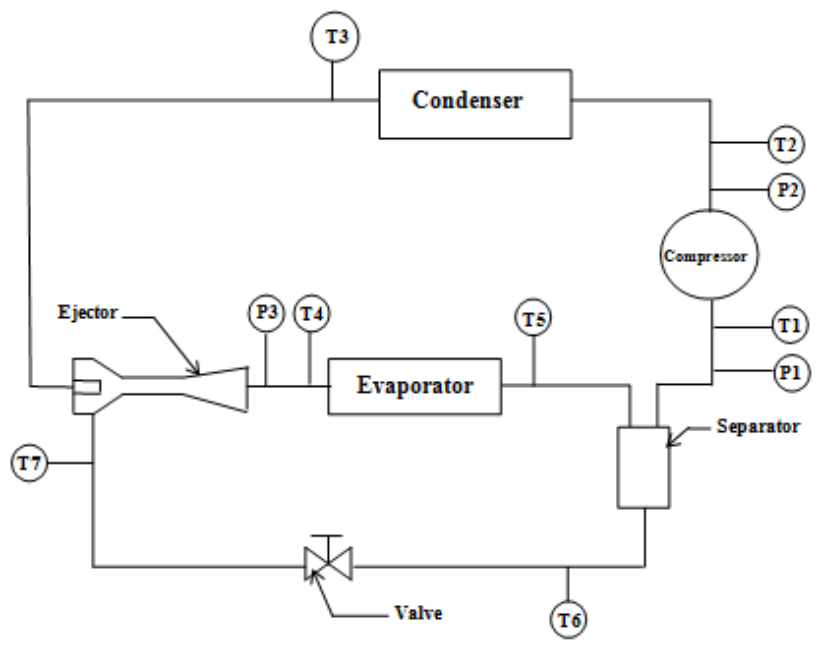

Fig. 5 Schematic of experimental setup with ejector

\subsection{Experimental procedure}

Initially valve was totally closed and tests were conducted. Temperature and pressure reading were taken at various positions, at the same time a wet and dry bulb temperature were calculated at lower and upper compartment of window air conditioner. Velocity of air was calculated using anemometer.

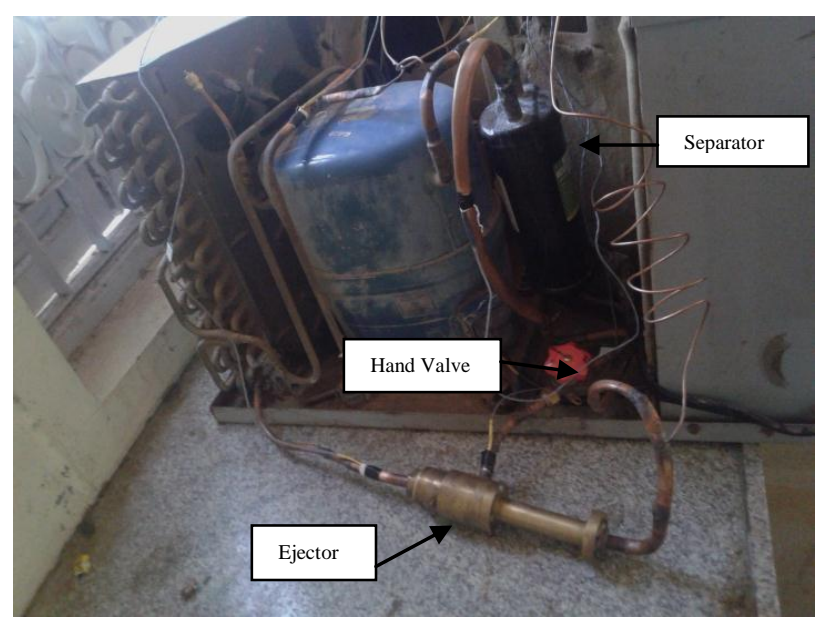

Fig. 6 Actual experimental setup

Now to re-circulate liquid refrigerant if any present at outlet of evaporator, valve was open gradually. Liquid refrigerant which was collected at the bottom, act as secondary flow to ejector. Hence, by adjusting the position of valve, pressure and temperature reading were noted.

\section{Results and discussion}

Various results were plotted by changing valve position. Hence seven positions were used 
i.e, $0 \%, 7 \%, 12.5 \%, 25 \%, 50 \%, 75 \%$ and $100 \%$.Therefore $0 \%$ indicates fully closed and $100 \%$ indicates fully open.

\subsection{Effect on compressor inlet temperature}

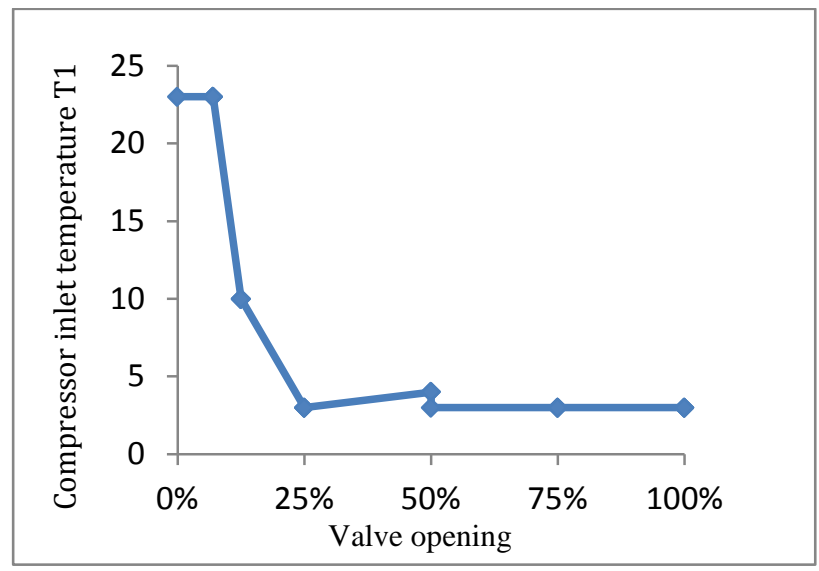

Fig. 7 Variation of compressor inlet temperature with valve opening

The above figure 7 shows variation of compressor inlet temperature at different valve opening position. It was seen that between 0 to $25 \%$ of valve opening compressor inlet temperature decreases randomly and afterward it almost remain constant for other valve opening position. It indicates that after 7\% opening of the valve there was reverse flow taking place from ejector to the separator. Therefore, the compressor inlet temperature decreases.

\subsection{Effect on Compressor outlet temperature}

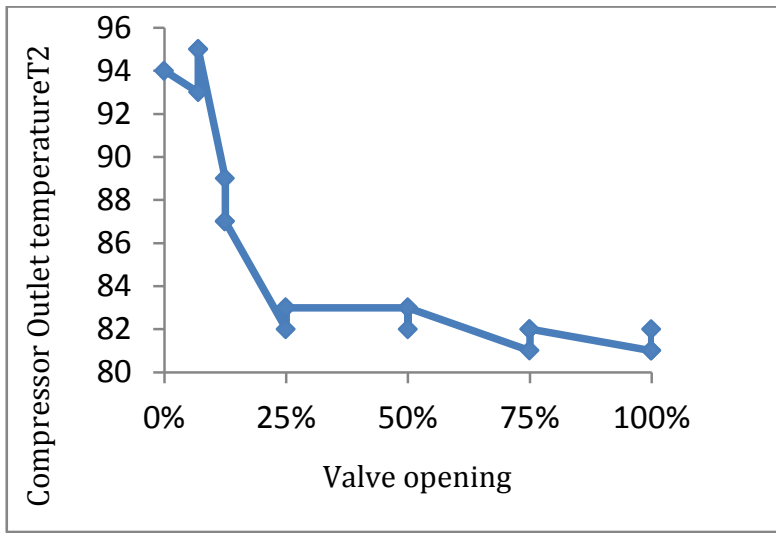

Fig. 8 Variation of compressor outlet temperature with valve opening

The above figure 8 shows the variation of compressor outlet temperature with different valve opening. Initially from 0 to $7 \%$ opening of valve the compressor outlet temperature increase and after that it decreases. This decrease in outlet temperature was due to decrease in inlet temperature in compressor as shown in figure 7.

\subsection{Effect on condenser outlet temperature}

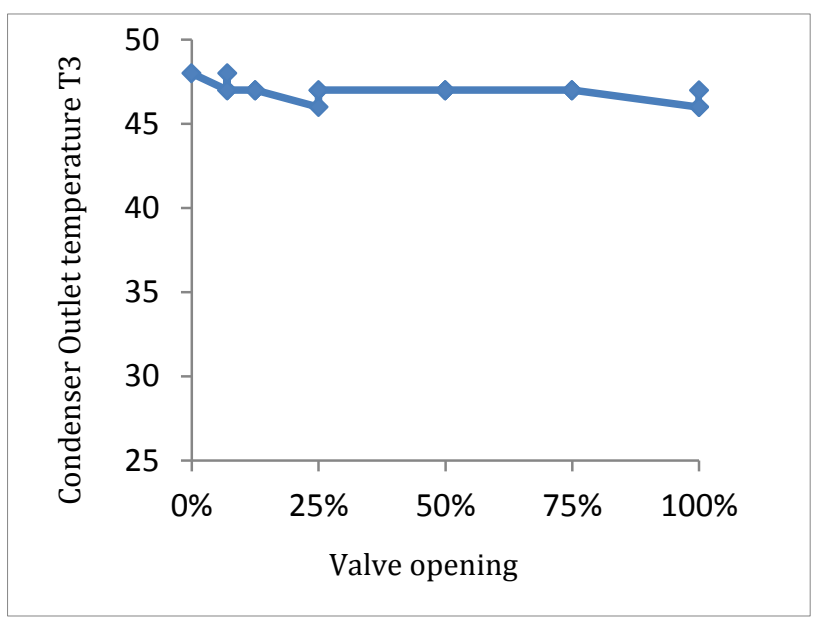

Fig. 9 Variation of condenser outlet temperature with valve opening

Figure shows the variation of condenser outlet temperature with different valve opening. Condenser Outlet Temperature remains almost constant at various valves opening position. This indicates that there is no effect of valve opening on condenser outlet temperature.

\subsection{Effect on Evaporator inlet temperature}

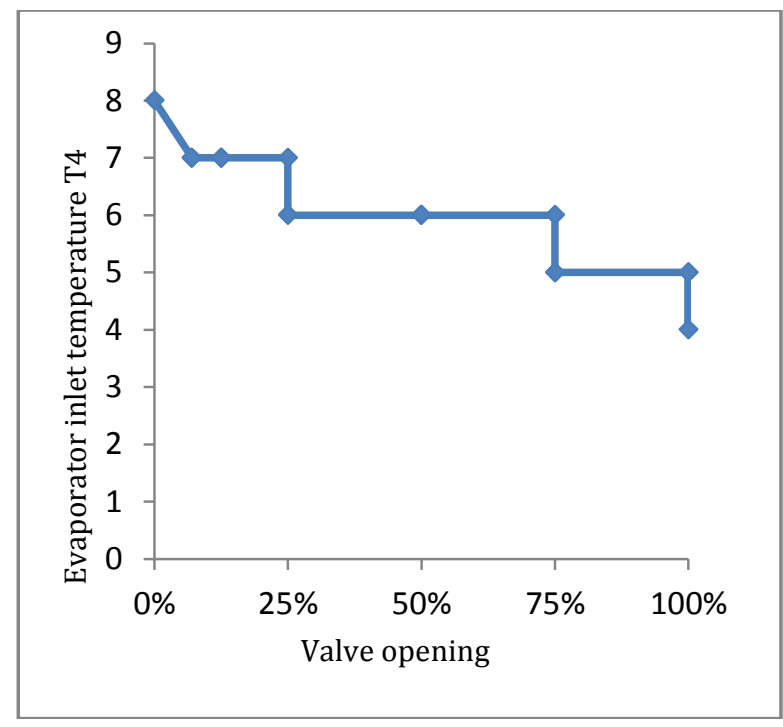

Fig. 10 Variation of evaporator inlet temperature with valve opening

Figure shows the variation of evaporator inlet temperature with different valve opening position Evaporator inlet temperature decreases with different valve opening position. Since after $7 \%$ opening of valve, there was reverse flow. Hence due to reduction in compressor inlet temperature, there was also drop in evaporator inlet temperature. 


\subsection{Effect on Evaporator outlet temperature}

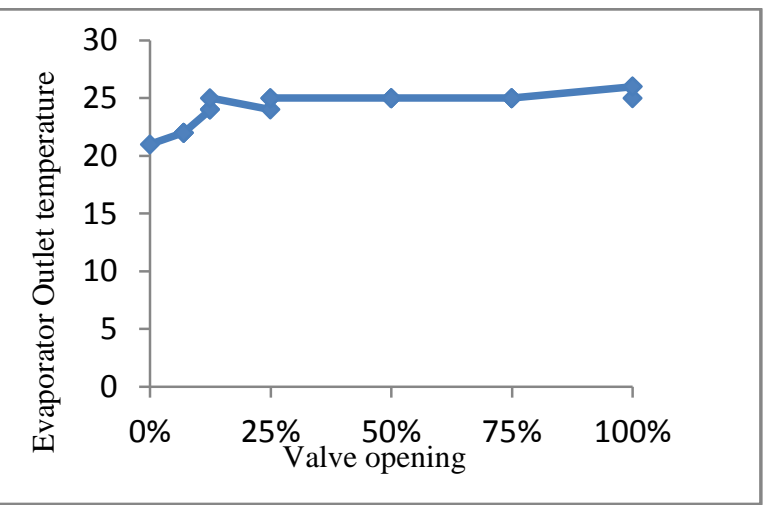

Fig. 11 Variation of evaporator outlet temperature with valve opening

Figure shows variation of evaporator outlet temperature with different valve position. It shows that evaporator outlet temperature increases with opening of valve. This shows that, there is superheating of refrigerant at outlet of evaporator due to reduced mass flow rate of refrigerant to evaporator.

\subsection{Effect on cooling capacity}

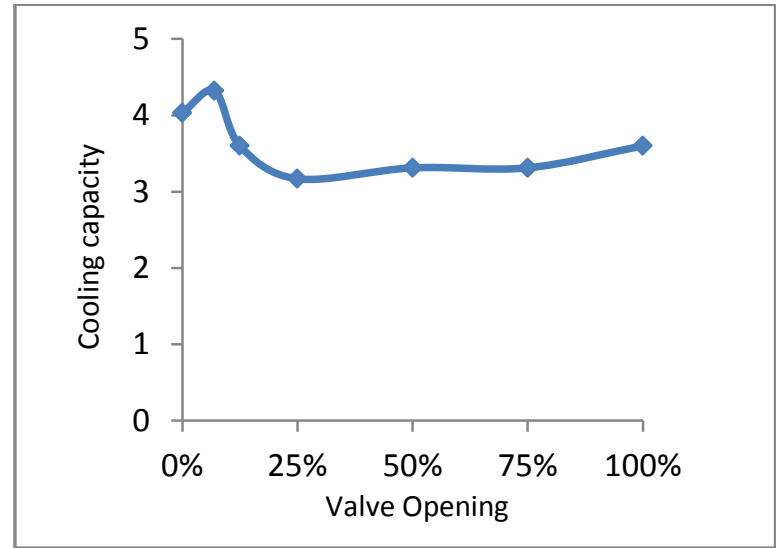

Fig. 12 Variation of cooling capacity with valve opening

Figure shows variation of cooling capacity at different valve opening. Cooling capacity first increases and then decreases. This was mainly due to reversed flow in system after $7 \%$ opening of the valve. At $7 \%$ opening of the valve maximum, cooling capacity was obtained. After that for almost all other positions, cooling capacity remains constant. Hence when valve was completely closed modified ejector refrigeration system shows improvement of $6 \%$ as compared with conventional cycle. But at $7 \%$ opening of valve it shows $14 \%$ improvement in cooling capacity as compared with vapour compression refrigeration cycle.

\subsection{Effect on actual COP}

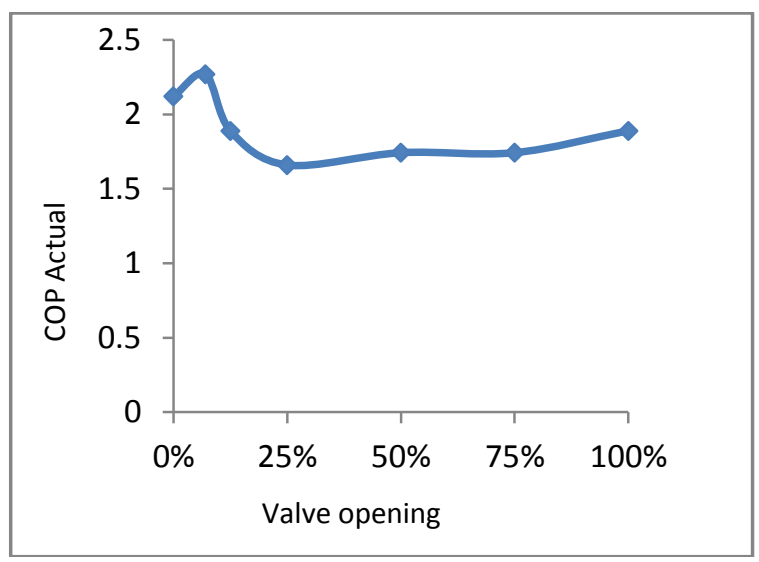

Fig. 13 Variation of Actual COP with valve opening

Figure shows variation of actual COP with different valve opening. COP increases first up to $7 \%$ opening of valve and then gradually decreases up to $25 \%$ opening of valve and then it almost remain constant from $25 \%$ to $100 \%$ opening of the valve. The actual COP of the system mainly increases due to increase in cooling capacity and decrease in power consumption.

\section{Conclusions}

The performance of window air conditioning system with modified ejector refrigeration system was been tested and analysed for different valve opening positions. The focus of this work was to increase the cooling capacity and decrease the power consumption.

Table 1 Comparison between two cycle performances

\begin{tabular}{|c|c|c|c|}
\hline Sr.no & Description & $\begin{array}{c}\text { Vapour } \\
\text { compression } \\
\text { refrigeration cycle }\end{array}$ & $\begin{array}{c}\text { Modified } \\
\text { Ejector } \\
\text { Refrigeratio } \\
\text { n cycle }\end{array}$ \\
\hline 1 & Cooling capacity & $3.789 \mathrm{~kW}$ & $4.32 \mathrm{~kW}$ \\
\hline 2 & Work input & $2 \mathrm{~kW}$ & $1.9 \mathrm{KW}$ \\
\hline 3 & $\begin{array}{c}\text { Coefficients of } \\
\text { performance }\end{array}$ & 1.89 & 2.27 \\
\hline
\end{tabular}

The experimental results shows that,

1) Cooling capacity of modified ejector refrigeration system at $7 \%$ opening of valve was increase by $14 \%$ over the conventional vapour compression refrigeration cycle of window air conditioning system.

2) Power consumption of modified ejector refrigeration system at $7 \%$ opening of valve was decrease by $5 \%$ over the conventional vapour compression refrigeration cycle of window air conditioning system.

3) The coefficient of performance of modified ejector refrigeration system at $7 \%$ opening of valve was 
increase by $20 \%$ over the conventional vapour compression refrigeration cycle of air conditioning system.

\section{References}

Jingwei Zhu and Stefan Elbel (2016), A New Control Mechanism for Two-Phase Ejector in Vapor Compression Cycles for Automotive Applications Using Adjustable Motive Nozzle Inlet Swirl, SAE International,2016-01-0243.

Disawas, S.; Wongwises S., (2004), Experimental investigation on the performance of the refrigeration cycle using a two-phase ejector as an expansion device. International Journal of Refrigeration, 27, 587-594.

Nehdi, E.; Kairouani, L.; Bouzaina, M.,(2007) Performance analysis of the vapour compression cycle using ejector as an expander. International Journal of Energy Recourses, 31, 364-375.

Bilir, N.; Ersoy H.K. ,(2009)Performance improvement of the vapour compression refrigeration cycle by two-phase constant area ejector. International Journal of Energy Recourses, 33, 469-480.
Pottker, G.; Hrnjak, P.,(2015) Ejector in R410A vapor compression systems with experimental quantification of two major mechanisms of performance improvement: Work recovery and liquid feeding. International Journal of Refrigeration, 50, 184-192.

Lawrence N.; Elbel, S., (2014),Experimental investigation of a two-phase ejector cycle suitable for use with low-pressure refrigerants R134a and R1234yf, International Journal of Refrigeration, 38, 310-322.

H. K. Kasni Sumeru, Shodiya Sulaimon, Henry Nasution, Farid Nasir Ani,(2014), Numerical and experimental study of an ejector as an expansion device in split-type air conditioner for energy savings., Energy and Buildings, 79,98-105.

Ersoy, N. Bilir Sag (2014), Preliminary experimental results on the R134arefrigeration system using a two-phase ejector as an expander, International Journal of Refrigeration 43, 97-110.

Coolpack(collection of simulation tools for refrigeration),Department of energy engineering, Technical university of Denmark. 